\title{
Delineation of Two Morphovariants of Cissus quadrangularis L. by Morphological, Anatomical and Biochemical Characters
}

\author{
Ashwathy G., Haritha Gopi, Ashmitha Ranjan, Aswathy K. M., Krishnakumar K* \\ Nutraceutical Research Division, Post Graduate and Research Department of Botany, Maharaja's College (Autonomous), India
}

Received March 25, 2020; Revised April 12, 2020; Accepted April 27, 2020

Copyright $\bigcirc 2020$ by authors, all rights reserved. Authors agree that this article remains permanently open access under the terms of the Creative Commons Attribution License 4.0 International License

\begin{abstract}
Cissus quadrangularis L. belongs to the family Vitaceae, commonly called bone setter plant. There are three morphovariants that exist for the species. They show many differences in their morphological appearances. Hence, the present study was carried out to delineate two morphovariants (variant I and III) of C. quadrangularis L. based on their morphological, anatomical and biochemical characters. As variant II is very rare, only two variants were taken for the present study. The two variants of $C$. quadrangularis L. showed differences in their morphological features like shape of the stem as well as that of leaves. The leaf, stem and aerial root anatomy also showed considerable differences. Biochemical studies like fluorescence analysis and nanoparticle assay were also carried out. The fluorescence study revealed that the two variants when treated with nitric acid showed significant differences in fluorescence. Nanoparticle assay of both the variants were carried out and showed considerable differences in their properties such as size and shape. Anatomical characters, nanoparticle properties as well as fluorescence properties can be used to delineate the two morphovariants. However molecular studies like DNA barcoding using different marker genes like ITS2, trnH-psbA, matK etc. could be carried out to precisely delineate the morphovariants. Further pharmacological evaluations are required to distinguish the medicinal properties of the two morphovariants.
\end{abstract}

Keywords Cissus quadrangularis, Morphovariant, Fluorescence, Nanoparticle

\section{Introduction}

Plants are unique components of nature showing a remarkable diversity and variation among the different species and also affected by the changeable environmental condition [1]. Nature has been a source of medicinal agents since the beginning of human civilization [2]. Medicinal plants or their derived material, have been widely employed in all cultures, throughout the history, for the prevention and treatment of diseases [3]. Recently there has been a tremendous increase in the use of plant-based health products in developing as well as developed countries resulting in an exponential growth of herbal products globally. Plants continue to serve as possible sources for new drugs and chemicals derived from various parts of plants. One of the many plants which are being evaluated for their therapeutic efficacies is $C$. quadrangularis L. which is commonly known as Hadjod (Bengali) and Edible Stemmed Vine (English) [4].

C. quadrangularis L. belongs to the family Vitaceae, which is a perennial plant commonly known as Veldt Grape or Devils backbone. It is an edible plant native to India and Africa and has been used medicinally for centuries. It is also widely seen in countries such as Pakistan, Sri Lanka, Malaysia, Thailand and Java. It is also known as Vitis quadrangularis Wall. [5,6,7]. Cissus is commonly known as "bone setter"; the plant is referred to as "Asthisamdhani" or "Asthishrunkala" in Sanskrit and "Hadjod" in Hindi because of its ability to join bones. As the name indicates it is commonly used in bone healing activity and well known in Ayurveda since long time [7].

C. quadrangularis L. has three morphovariants based on the differences in their morphological characters; square-stemmed - Variant I, round-stemmed - Variant II and flat stemmed- Variant III. The square-stemmed and round-stemmed variants are the most commonly available and it grows almost everywhere in India. The round-stemmed variant termed as variant II is characterized by the presence of wingless stem. It is found rarely. The internode is four sided and depressed slightly on four sides. Variant III which is flat- stemmed is the flat 
stemmed variant $[8,9,10]$.

The present study focuses on the delineation of the morphovariants of C. quadrangularis L. by morphological, anatomical and biochemical characters. Morphological, anatomical and biochemical studies are carried out in order to distinguish species within a genus or subspecies and morphotypes within species. Plant biologists use morphological characters of plants to assess the differences or similarities in plant taxa and use these characters for their identification, classification and description $[11,12]$. Anatomical characters can also be used as a tool for the identification of the plant species. Use of biochemical characters are also of great importance for distinguishing plant species.

Properties like Fluorescence behaviour, structure and properties of biosynthesized nanoparticles can be used to distinguish species [13]. Nowadays plant extracts act as reducing as well as capping agents for the synthesis of nanoparticles which is more advantageous than chemical and microbial synthesis. Biological methods of nanoparticle synthesis by using microorganisms such as bacteria, fungus, algae, enzymes and plants both intra-cellularly and extra-cellularly is an eco-friendly process. Among the metal nanoparticles silver has been consumed largely due to their antimicrobial and pharmaceutical applications. The most important application of silver and silver nanoparticles is in medical industry such as topical ointments to prevent infection against burn and open wounds. Medical devices and implants were prepared with silver impregnated polymers and antibiotics. The small sized nanoparticles have large surface area to improve the antimicrobial activity in addition to improving chemical stability. Nowadays silver can also be utilized either in the textile industry by incorporating it in to the fibre or employed in filtration membranes of water purification systems $[14,15]$.

\section{Materials and Methods}

\subsection{Collection and Identification of the Plant Material}

The two morpho-variants of $C$. quadrangularis $\mathrm{L}$. were collected from two different locations. The variant I was collected from the Botanical Garden, Maharaja's College, Ernakulam, Kerala (India) on $12^{\text {th }}$ December, 2018 and variant III was collected from Aromatic and Medicinal Plant Nursery, Kerala Agricultural University, Odakkali, Perumbavoor, Ernakulam, Kerala, India on $15^{\text {th }}$ December, 2018. Variant III were then grown in earthen pots in the Botanical Garden, Maharaja's College, Ernakulam, Kerala (India). There was no voucher specimens prepared but digitally recorded. The specimens were identified with authentic taxonomic literature. From the freshly collected samples, the morphological and anatomical studies were carried out. For the fluorescence and silver nanoparticle studies, the powdered samples were used. The plant materials were washed thoroughly to get rid of dust particles in running tap water, cut in to smaller pieces, shade dried, powdered and stored in air tight containers for further studies.

\subsection{Morphological Study}

The morphological characters of variant I and variant III of C. quadrangularis L. were studied. Habit, stem, leaf, root, internodal length, stomatal type and stomatal index were studied. Flowers were not observed for the variants during the period of study.

\subsection{Anatomical Study}

Leaf peeling was observed under the microscope to find out the stomatal type. Stomatal index was also calculated. Free hand transverse sections of stem, leaf, aerial root of $C$. quadrangularis L. variant I and variant III were taken, stained with safranin and mounted in glycerine and observed under light microscope (Biolinkz M2000 series) and photographed at 10X and 40X.

\subsection{Fluorescence Analysis}

Fluorescence assay was conducted as described elsewhere [2]. Behaviour of powdered stem samples of $C$. quadrangularis $\mathrm{L}$. variant I and variant III with different chemical reagents were assayed. The colour changes were observed for the powder of variant I and variant III under the visible light and UV- light when treated with different chemical reagents. The powdered sample of both variant I and variant III were taken in separate glass slides and treated with a few drops of different chemical reagents like distilled water, acetic acid, Sodium hydroxide, concentrated Hydrochloric acid, concentrated nitric acid, concentrated Sulphuric acid, Ammonium hydroxide and Iodine solution. The colour change was visualized under visible light and UV light in UV chamber.

\subsection{Silver Nanoparticle Assay}

Silver nanoparticle assay was carried out in order to find out whether both the variants of Cissus quadrangularis $\mathrm{L}$. (variant I and variant III) synthesized nanoparticle or not. Only the preliminary confirmation and microscopical observation of biosynthesized nanoparticles were carried out.

The stem cuttings of both the variant were collected, washed thoroughly in distilled water to wash away dust particles, shade dried for 2 weeks and after drying it was finely powdered. The powdered samples were stored in air tight containers for further study.

\subsubsection{Preparation of Silver Nitrate Solution}


$2 \mathrm{mM}$ silver nitrate solution was prepared by adding $0.0339 \mathrm{gm}$ of silver nitrate in $100 \mathrm{ml}$ of double distilled water. The solution was mixed thoroughly and stored in brown colored bottle in order to prevent auto-oxidation of silver.

\subsubsection{Preparation of the Plant Sample Extract}

$25 \mathrm{gm}$ of the powdered sample of both variants were taken in separate $250 \mathrm{ml}$ beakers and boiled along with 100 $\mathrm{ml}$ distilled water. After 10minutes of boiling, solution was cooled to room temperature and filtered using Whatman's No.1 filter paper. The collected extracts were used for the synthesis of silver nanoparticles.

\subsubsection{Synthesis of Silver Nanoparticles}

$10 \mathrm{ml}$ of each extract (of variant I and variant III) was added to $90 \mathrm{ml}$ of $2 \mathrm{mM}$ aqueous silver nitrate solution (1:9 ratio) and mixed thoroughly by manual shaking. The beakers were then placed under sunlight for reduction in to silver nanoparticle. After 10 minutes colour changes were noted for each variant. This indicates the preliminary conformation for the formation of plant- mediated silver nanoparticle [16].

\subsubsection{Purification of Silver Nanoparticles}

After $5 \mathrm{hrs}$ grey coloured nanoparticle starts to settle at the bottom. The solution was centrifuged at $8000 \mathrm{rpm}$ for 15 minutes, supernatant was discarded and pellet containing nanoparticles were taken. Pellet was washed thrice with distilled water by centrifugation. Finally, the pellets were taken out on a petri-plate and kept in hot air oven to dry at $50^{\circ} \mathrm{C}$ for $4-5 \mathrm{hrs}$. The nanoparticles were then taken out on a glass slide and observed under $40 \mathrm{X}$ resolution of the microscope and photographs were taken for both the variants.

\section{Results}

\subsection{Morphological Characters}

The variants of $C$. quadrangularis $\mathrm{L}$. were collected from two different locations (Figure 1). Specimens were identified using standard authentic literature $[10,17]$. The morphological characters of two variants of Cissus quadrangularis $\mathrm{L}$. showed some differences in characters of stem, leaf, root and tendril (Table 1). The stem of variant I is four angled and that of variant III is flat shaped. Leaf of variant I is simple and that of variant III is lobed. The characters of root were similar in two variants, both showed tap root system. The internodal length is also similar in both variants.

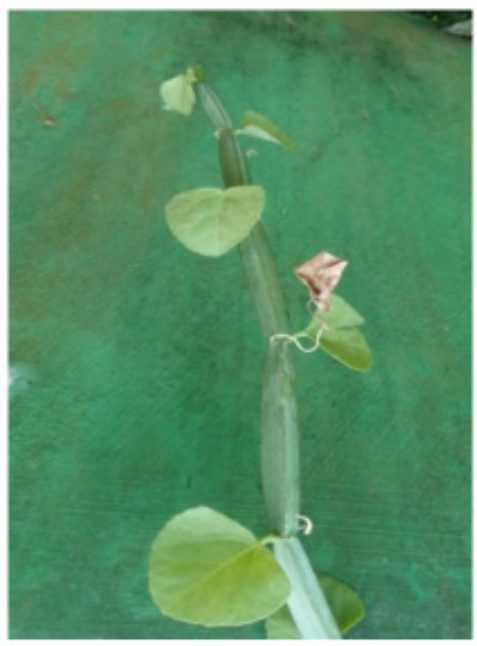

a.

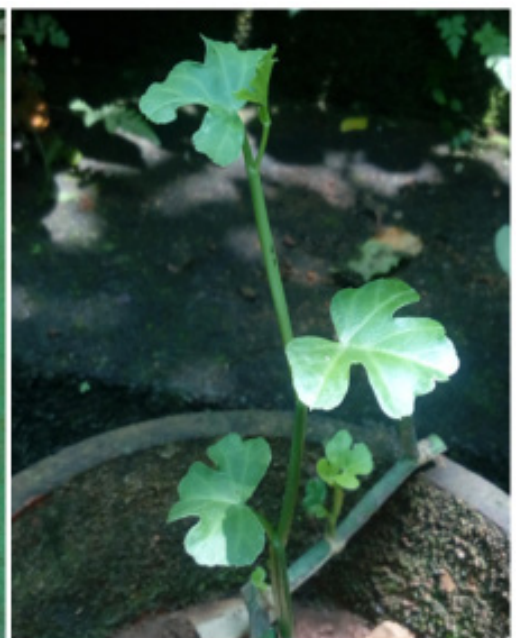

b.

Figure 1. a. Habit of variant I; b. Habit of variant III

Table 1. Morphological characters of two variants of C. quadrangularis $\mathrm{L}$

\begin{tabular}{|c|c|c|c|}
\hline Sl.no. & Characters & Variant I & Variant III \\
\hline 1 & Habit & Climber & Climber \\
\hline 2 & Stem & $\begin{array}{c}\text { Quadrangular stem up to } 12 \text { meters long } \\
\text { from tuberous root stock }\end{array}$ & $\begin{array}{c}\text { Flat stems up to 12meters long from a } \\
\text { tuberous root stock }\end{array}$ \\
\hline 3 & Leaf & Simple alternate, $4 \pm 1.5 \mathrm{~cm}$ & Alternate palmate, $4 \pm 1.5 \mathrm{~cm}$ \\
\hline 4 & Root & Tap root: $11 \pm 1 \mathrm{~cm}$ & Tap root: $9 \pm 2.7 \mathrm{~cm}$ \\
\hline 5 & Internodal length & $7 \pm 0 \mathrm{~cm}$ & $7 \pm 0 \mathrm{~cm}$ \\
\hline
\end{tabular}



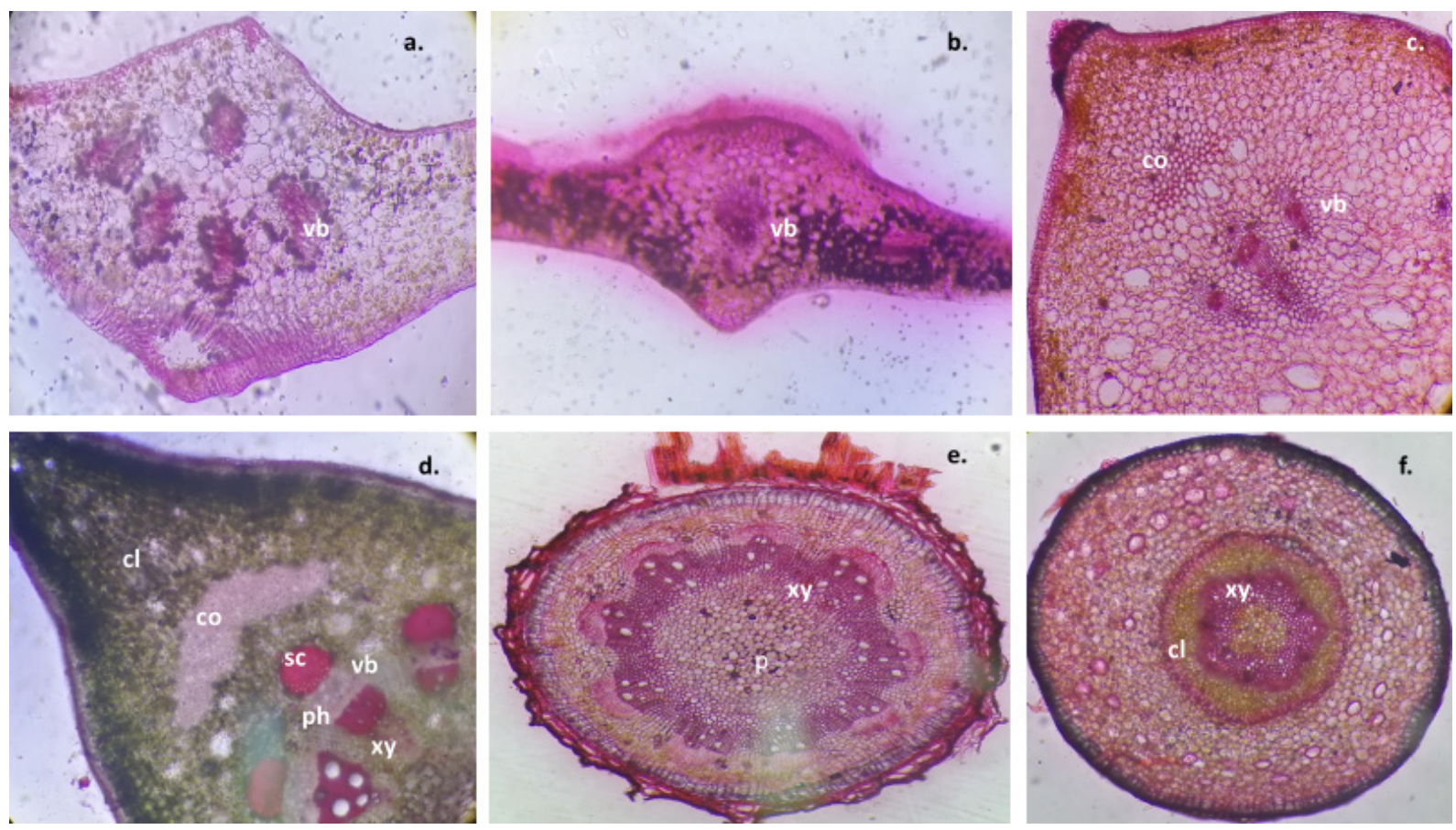

vb- vascular bundle, cl- chlorenchyma, co- collenchyma, sc- sclerenchyma, ph- phloem, xy- xylem, p-pith

Figure 2. a. T.S of Leaf of Variant I; b. T.S of Leaf of Variant III; c. T.S of Stem of Variant I; d. T.S of Stem of Variant III; e. T.S of Aerial root Variant I; f. T.S of Aerial root Variant III

\subsection{Anatomical Characters}

The stomatal type seen in both the variants were anomocytic. Both the upper and lower stomatal index were also calculated. For variant I, the upper stomatal index was found to be 18.42 and lower stomatal index was found to be 19.61. For variant III, the upper stomatal index was found to be 18.44 and lower stomatal index was found to be 22 . 64. Surface indumentum were not observed in both the variants.

Free hand sections of leaf, stem and aerial root were prepared and observed under microscope (Figure 2). Tendrils were not observed in variant 3 . The anatomical study of variants I and III of C. quadrangularis $\mathrm{L}$. were carried out and the results observed are as follows:

\subsubsection{Transverse Section of Leaf of C. quadrangularis $\mathrm{L}$. Variant I}

The section showed characters like thin epidermal layer of small thick-walled squarish cell. The ground tissue in the adaxial part is small circular and thick- walled. In other region of the mid rib, the ground tissue was disintegrated leaving only small lobed parenchyma cell. The vascular system of the mid rib consisted of four radiating arms of vascular strands. Mucilage cell were observed in the mid rib. Vascular bundles were centrally located. The number of vascular bundles varied from basal of apical region of the leaf. 3-5vascular bundles are seen in the mid rib region. A collenchymatous cap was present over each vascular bundle. Vascular bundles are open, collateral and endarch. Stomatal openings were observed on the adaxial surface.
Stomatal type was found to be anomocytic and stomatal index of the upper leaf surface is 18.42 and that of lower was 19.61 .

\subsubsection{Transverse Section of Leaf of C. quadrangularis $\mathrm{L}$. Variant III}

Transverse section of leaf of variant III was somewhat similar to variant I. The section had an outer epidermis followed by collenchymatous zone, parenchymatous ground zone and centrally located vascular zone. The epidermal cell in the abaxial surface and adaxial protuberance region were simillar in size, square to rectangular in shape 2-6 layer of collenchyma cells were seen in the abaxial surfaces. There were compactly arranged, small, polygonal to round shaped. Mucilage cells were also observed in the midrib region. Vascular bundles are centrally located. There was only a single vascular bundle observed in the mid rib region. A collenchymatous cap was seen over each vascular bundle. Bundles are open collateral endarch. Stomata were anomocytic in variant III also. The stomatal index of the upper leaf surface was 18.44 and that of lower surface were 22.64 which are somewhat similar to the stomatal index of variant I.

\subsubsection{Transverse Section of Stem of C. quadrangularis $\mathrm{L}$. Variant I}

The transverse section of stem of variant I showed three zones namely cortex, vascular bundles and pith. The outline of the stem T.S was somewhat dumb bell shaped. The four corners are extended forming the wing of stem. It consists of a single layered epidermis which was 
surrounded by the cuticle. Epidermis was followed cortex. Cortex was differentiated in to outer chlorenchymatous layer and inner parenchymatous layer. Large mucilage cells were observed in the cortex. Patches of collenchyma were seen embedded in chlorenchymatous layer at each corner. The four corners of the stem were occupied by four vascular bundles each. Vascular bundles were collateral, open and endarch. Sclerechymatous cap was present above the phloem of each bundle. The vascular bundles along the sides were smaller than those corners. Medullary rays were seen between each vascular bundle. Pith was comparatively large occupying most of the area and was parechymatous. Large mucilage cells were also seen in the pith region.

\subsubsection{Transverse Section of Stem of C. quadrangularis $\mathrm{L}$. Variant III}

The transverse section of stem showed three zones namely cortex, vascular bundle and broad pith. The outline of stem T.S was somewhat triangular in shape. It consists of a single layered epidermis which was surrounded by cuticle. Epidermis was followed by 5-6 layers of chlorenchymatous hypodermis. Like variant I large mucilage cells were observed in the cortex. Patches of collenchyma were seen embedded in the chlorenchymatous hypodermis. The three corners of stem were occupied by three vascular bundles each. Vascular bundles are collateral, open and endarch. Cambium was present between xylem and phloem of each bundle. Medullary rays were seen between each vascular bundle. Pith was parenchymatous and also carried mucilage cells.

\subsubsection{Cross Section of Aerial Root of C. quadrangularis Variant I}

Cross section of aerial root showed mainly three zones: periderm, vascular tissue and pith. The cross section of aerial root showed secondary thickening. The epidermis and cortex had been disintegrated due to secondary thickening. Phellum, phellogen and phelloderm were formed. Phellum was a dead tissue and have a lot of air-filled spaces. Phellogen was composed of 3 layers. Phelloderm was 5-6 layers thick which was composed of chlorenchyma cells, vascular bundle was 9 in number. Due to secondary thickening medullary rays had been formed also secondary xylem and secondary phloems were developed. Pith was comparatively large and was formed of a parenchymatous tissue.

\subsubsection{Cross Section of Aerial Root of C. quadrangularis Variant III}

Cross section of aerial root of Cissus quadrangularis variant III showed three major zones: periderm, vascular tissue and pith. The section that was taken showed secondary thickening. As in variant I the epidermis and cortex have been disintegrated into phellum, phellogen, and phelloderm. Phellum and phellogen were seen as a single layer, but phelloderm consists of 5-6 layer of chlorenchymatous tissue. It followed by a 2-3 layers of chlorenchymatous tissue. Vascular bundles are 9 in number. Due to secondary thickening medullary rays were also developed. Pith was parenchymatous.

\section{Biochemical Properties}

\subsection{Fluorescence Analysis}

The fluorescence analysis of the two variants were carried out. The behaviour of the powdered sample with different chemical reagents were observed. $0.1 \mathrm{gm}$ of each powdered samples of both the variants were treated with various chemical reagents like distilled water, sodium hydroxide, ammonium hydroxide, acetic acid, concentrated hydrochloric acid, iodine solution and nitric acid and were observed under visible as well as ultraviolet light (in UV chamber). The result of the fluorescence study is given in Table 2 and 3.

Table 2. Fluorescence properties of C. quadrangularis L. Variant I

\begin{tabular}{|c|c|c|}
\hline Particulars & Visible light & UV light \\
\hline Powder + Distilled water & Light brown & Reddish brown \\
\hline Powder $+\mathrm{NaOH}$ & Light green & Light green \\
\hline Powder $+\mathrm{NH}_{4} \mathrm{OH}$ & Light green & Yellowish green \\
\hline Powder + Acetic acid & Light green & Pale green \\
\hline Powder + conc. $\mathrm{HCl}$ & Dark green & Dark green \\
\hline Powder + Iodine & Dark green & Black \\
\hline Powder $+\mathrm{HNO}_{3}$ & Light red & Dark red \\
\hline
\end{tabular}

Table 3. Fluorescence properties of C. quadrangularis L. Variant III

\begin{tabular}{|c|c|c|}
\hline Particulars & Visible light & UV light \\
\hline Powder + Distilled water & Light brown & Reddish brown \\
\hline Powder $+\mathrm{NaOH}$ & Light green & Light green \\
\hline Powder $+\mathrm{NH}_{4} \mathrm{OH}$ & Light green & Yellowish green \\
\hline Powder + Acetic acid & Light green & Pale green \\
\hline Powder + conc. $\mathrm{HCl}$ & Dark green & Dark green \\
\hline Powder + Iodine & Dark green & Black \\
\hline Powder $+\mathrm{HNO}_{3}$ & Light red & Yellow \\
\hline
\end{tabular}

Most of the results obtained from the fluorescence study were similar for both the variants. The powder showed colour differences in UV light when treated with chemicals such as conc. Sulphuric acid, Ammonium hydroxide, Acetic acid, Iodine, and Nitric acid. These colour changes were similar for both the variants except with nitric acid variant I gave dark red in UV light and variant III showed yellow colour in UV light.

\subsection{Silver Nanoparticle Assay}


Green syntheses of silver nanoparticle were shown by both the variants of $C$. quadrangularis $\mathrm{L}$. For variant I the colour change observed after adding silver nitrate solution was from pale yellow to reddish brown (Figure 3). For variant III, the colour change was from light yellow to red. After 5 hours the nanoparticle of both variants settled at the bottom and was centrifuged at $8000 \mathrm{rpm}$ and washed. The intensity of the colour change is representative of the amount of silver nanoparticle synthesized. The size of nanoparticle synthesised with variant I was higher when compared to the variant III. The size and shape of nanoparticles were also different for each variant. Under $40 \mathrm{X}$ resolution of the microscope, the nanoparticles produced by variant I was found to be almost round in shape and larger in size when compared with variant III. Nanoparticles of variant III were of two types round and rod shaped and lesser in size when compared to that of variant I.

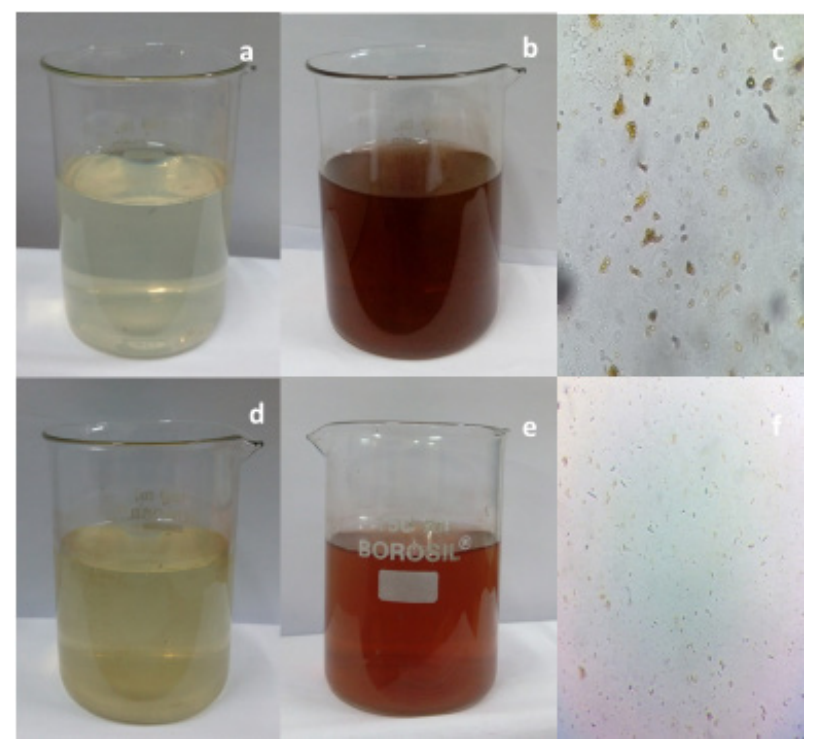

Figure 3. Nanoparticle Assaay of C. quadrangularis L.Variant I and Variant III: a \& b Colour change observed for Variant I; d \& e Colour change observed for Variant III; c. Size and shape of the nanoparticle synthesized by Variant I; f. Size and shape of the nanoparticle synthesized by Variant III

\section{Discussion}

Cissus quadrangularis L. is a well- known medicinal plant that has the capacity to heal bone fractures. There are three morphophovariants present for the species. The present study dealt with delineating the species based on morphological, anatomical and biochemical characters. The study of morphological characters revealed that only stem and leaf are with significant morphological differences. This indicates that both the variants showed differences in their habit even if other parameters studied were almost similar. Earlier reports showed that plants with same morphological features may vary in their biochemical properties [10].
As the morphological characters showed little differences, we conducted the anatomical studies of stem, aerial root and leaf. The anatomical studies of the stem revealed that significant difference in the orientation of vascular bundles (Figure 2). In Variant I there is a peripheral layer of vascular bundles, in addition the corners were occupied by the four vascular bundles each. In case of variant III the corners were occupied by three vascular bundles each. This indicates that the difference was observed among the two variants studied. Earlier works reported that anatomical differences can be used to distinguish the medicinal plant varieties [18].

The study of aerial root revealed that no significant difference in the orientation of different tissues except variant I with a comparatively larger pith. In the present investigation, the anatomical characters of the leaf were also analyzed. The leaf anatomy showed significant difference $i e$., in variant $\mathrm{I}$, the midrib region carried 5 vascular bundles, however in variant III, the midrib region carries 1 vascular bundle. Hence, this can be used to distinguish two plants. Earlier workers reported that anatomical characters can be used as a key to distinguish different morphotypes [19].

Earlier workers have demonstrated that plants with same characters may show differences in fluorescence behaviour $[2,11]$. As C. quadrangularis $\mathrm{L}$. was well known for its pharmacological properties $[4,6,20,21]$, we assayed fluorescence properties of both the variants. Both the variants showed almost similar properties towards visible as well as UV light. However, when treated with nitric acid showed significant difference towards fluorescence with UV light ie., variant I showed dark red while variant II showed yellow fluorescence. There were reports that the variants with light indicate that both the variants have almost same chemical profile $[2,22,23]$.

Plant compounds react with silver nitrate and produce silver nanoparticles. These nanoparticles can be used for various studies including pharmacological evaluation $[14,15,24,25,26]$. The present study demonstrated only the biosynthesis of the silver nanoparticles by the extracts of variant I and variant III ie. if the extracts produced nanoparticles on addition of $0.2 \mathrm{M}$ silver nitrate solution. Further studies have to be carried out including UV- Vis spectroscopic studies, Dynamic Light Scattering studies, Transmission electron microscopic studies, Fourier Transform Infra- red Spectroscopic studies etc., have to be carried out in order to find the actual size and shape of the silver nanoparticles synthesized

In the present investigation we could delineate the two morphovariants of $C$. quadrangularis $\mathrm{L}$. based on morphological, anatomical as well as biochemical characters. However, further studies are required to ascertain the differences in pharmacological properties of the two morphovariants. 


\section{Conclusions}

The two morphovariants of Cissus quadrangularis L. could be delineated based on the morphological, anatomical and biochemical characters. Further pharmacological evaluation is also required to distinguish the medicinal properties of the two morphovariants. Further investigations of the silver nanoparticles using UVVis spectroscopic studies, Dynamic Light Scattering studies, Transmission electron microscopic studies, Fourier Transform Infra- red Spectroscopic studies etc. are required to ascertain the present results. In addition, molecular studies like DNA barcoding using different marker genes like ITS2, trnH-psbA, matK etc. could be carried out to precisely delineate the morphovariants.

\section{Acknowledgement}

The authors are grateful Medicinal Plant Nursery, Kerala Agricultural University, Odakkali, Perumbavoor, Ernakulam, Kerala, India for providing one of the morphovariants.

\section{REFERENCES}

[1] Patel D. K. Mass vegetative propagation of Cissus quadrangularis L. in Herbal Garden. The Pharma Innovation Journal, 4 (10): 09-12, 2015.

[2] Alok Semwal, Senthil Kumar M. Development of quality control parameters for the standardization of Leaves and bark of Sida acuta Burm.f. Indian Journal of Pharmaceutical and Biological Research, 2 (4): 89- 93, 2014.

[3] Sumitra Chanda, Yogesh Baravalia, Krunal Nagani. Spectral analysis of methanol extract of Cissus quandrangularis L., stem and its fraction. Journal of Pharmacognosy and Phytochemistry, 2(4):149-157,2013.

[4] Monokesh Kumar Sen, Biplab Kumar Dash. A review on phytochemical and pharmacological aspect of Cissus quadrangularis L. International Journal of Green Pharmacy, 6:169-173,2012.

[5] Jarupla Surender, Ashok Kumar A., Nagaghusan Reddy. Effect of studies in processing and preservation of Cissus quadrangularis for value added powder-based product and their storage stability. Journal of Pharmacognosy and Phytochemistry, 27(2): 955-958, 2018.

[6] Rahul Shukla, Anup Pathak, Kambuja S., Sandeep Sachan, Ashutosh Mishra, Sankul Kumar. Pharmacognostical, Phytochemical and Pharmacological Overview: Cissus quadrangularis Linn. Indian Journal of Pharmaceutical and Biological Research, 3(3): 59-65, 2015.

[7] Krunal Nagani, Vignesh Kevalia J, Sumitra Chanda V. Pharmacognostical and phytochemical evaluation of stem of Cissus quadrangularis L. International Journal Pharmaceutical Sciences and Research, 2(11): 2856-2862,
2011.

[8] Sathish Kumar T., Anandan A., Jegadeesan M. Identification of chemical compounds in Cissus quadrangularis L. Variant-I of different sample using GC-MS analysis. Archives of Applied Science Research, 4 (4): 1782- 1787, 2012.

[9] Anoop Austin, Kannan R., Jegadeesan M. Pharmacognostical studies on Cissus quadrangularis L.Variant I and variant II. Ancient science of life, 23(4): 33-47, 2004.

[10] Ansarali S., Manikandan S., Alagu Lakshmanan G. M. Comparative morphological and phytochemical analyses of three variants of Cissus quadrangularis in Tamil Nadu. International Journal of Pharmacy and Biological Sciences, 8 (3): 579-592, 2018.

[11] Elshihy O. M., Sharaf A. N., Muzher B. M. Morphological, anatomical and biochemical characterization of Syrian pear (Pyrus syriaca Boiss) genotypes. Arabian Journal of Biotechnology,7 (2): 209-218, 2004.

[12] Krishnakumar. K., Rajeena. P., Veena. V. Study on diversity of foliar trichomes in thirty accessions of okra (Abelmoschus esculentus (L.) Moench.). Indian Journal of Agricultural Research. 52 (4): 439-443, 2018.

[13] Kamiar Zomorodian, Mohammad Pourshahid Seyed, Arman Sadatsharifi, Pouyan Mehryar, Keyvan Pakshir, Mohammad Javad Rahimi, Ali Arabi Monfared. Biosynthesis and Characterization of Silver Nanoparticles by Aspergillus Species. BioMed Research International, Article ID 5435397, 2016.

[14] Vanaja Mahendran, Gnanajobitha Gnanadhas, Paulkumar Kanniah, Rajeshkumar Shanmugam, Malarkodi Chelladurai, Annadurai Gurusamy. Phytosynthesis of silver nanoparticles by Cissus quadrangularis: influence of physicochemical factors. Journal of Nanostructure in Chemistry, 3 (17): 1-8, 2013.

[15] Abhishek Bhattacharjee. Synthesis and applications of silver nanoparticles in health care. International Journal of Innovative Pharmaceutical Sciences and Research, 3 (12), 1719-1733, 2015.

[16] Gamble J. S. Flora of the Presidency of Madras. Volume 2, London: West, Newman and Adlard, 1915.

[17] Nisha C., Bhawana P., Fulekar M. H. Antimicrobial Potential of Green Synthesized Silver Nanoparticles Using Sida acuta Leaf Extract. Nano Science \& Nano Technology: An Indian Journal, 11(1): 1-9, 2017.

[18] Josiane Claudino C., Luis Do Sacramento V.S., Ingrid Koch, Helen Santos A., Alberto Cavalheiro J., Aristeu Tininis G., André Dos Santos G. Evaluation of morpho-anatomical and chemical differences between varieties of the medicinal plant Casearia sylvestris Swartz. Annals of the Brazilian Academy of Sciences, 85(4): 1253-1265, 2013.

[19] Paweena Traiperm, Janene Chow, Possathorn Nopun, Staples G., Sasivimon Swangpol C. Identification among morphologically similar Argyreia (Convolvulaceae) based on leaf anatomy and phenetic analyses. Botanical Studies, 58(25): 1-14, 2017.

[20] Garima Mishra, Saurabh Srivastava, Nagori B.P. 
Pharmacological and Therapeutic Activity of Cissus quadrangularis: An Overview. Inernational Journal of Pharm Tech Research, 2 (2): 1298-1310, 2010.

[21] Mohammed Ghouse Shakir. A Pharmacognostical review on Ciccus quadrangularis Linn. International Journal of Research in Pharmacy and Biosciences,2 (7): 28-35, 2015.

[22] Sathish Kumar T., Jegadeesan M. Physio-chemical profile of Cissus quadrangularis L. var- I in different soils. Ancient Science of Life, 26 (1\&2): 50-58, 2006.

[23] Vijayalakshmi A, Kumar P. R., Sakthi Priyadarsini S., Meenaxshi C. Pharmacognostic and phytochemical investigation of the aerial parts of Cissus quadrangularis Linn. Journal of Scientific and Innovative Research, 2 (5): 872-879, 2013.
[24] Sudharameshwari K., Maheshwari V. Cissus quadrangularis extract mediated green synthesis of silver nanoparticles: pharmacological applications. Indian Journal of Medical Research and Pharmaceutical Sciences, 4(8): 30$36,2017$.

[25] Renugadevi K., Inbakandan D., Bavanilatha M., Poornima V. Cissus quadrangularis assisted biosynthesis of Silver Nanoparticles with antimicrobial and anticancer potentials. International Journal of Pharma and Bio Sciences, 3(3): 437 $-445,2012$.

[26] Sivakama Valli J., Vaseeharan B. Biosynthesis of silver nanoparticles by Cissus quadrangularis extracts. Materials Letters, 82:171-173, 2012. 